

\title{
Identification and characterization of mature $\beta$-hexosaminidases associated to human placenta lysosomal membrane
}

Alessandro Magini, Simona Mencarelli, Brunella Tancini, Virginia V

Ciccarone, Lorena Urbanelli, Andrej Hasilik, Carla Emiliani

\section{To cite this version:}

Alessandro Magini, Simona Mencarelli, Brunella Tancini, Virginia V Ciccarone, Lorena Urbanelli, et al.. Identification and characterization of mature $\beta$-hexosaminidases associated to human placenta lysosomal membrane. Bioscience Reports, 2008, 28 (4), pp.229-237. 10.1042/BSR20080075 . hal00479302

\section{HAL Id: hal-00479302 https://hal.science/hal-00479302}

Submitted on 30 Apr 2010

HAL is a multi-disciplinary open access archive for the deposit and dissemination of scientific research documents, whether they are published or not. The documents may come from teaching and research institutions in France or abroad, or from public or private research centers.
L'archive ouverte pluridisciplinaire HAL, est destinée au dépôt et à la diffusion de documents scientifiques de niveau recherche, publiés ou non, émanant des établissements d'enseignement et de recherche français ou étrangers, des laboratoires publics ou privés. 


\title{
Identification and characterization of mature $\beta$-hexosaminidases associated to human placenta lysosomal membrane
}

\begin{abstract}
Alessandro MAGINI* $\dagger$, Simona MENCARELLI ${ }^{\star} \dagger$, Brunella TANCINI*, Virginia CICCARONE*, Lorena URBANELLI*, Andrej HASILIK‡, Carla EMILIANI*1
\end{abstract}

*Department of Experimental Medicine and Biochemical Sciences, University of Perugia, via del Giochetto, 06126 Perugia, Italy, and ¥ Institut fur Physiologische Chemie, Philipps-University Marburg, Karl-von-Frisch-Strasse 1, 35033 Marburg, Germany.

Short Title: lysosomal membrane associated $\beta$-hexosaminidases

†To be considered as equal first authors.

${ }^{1}$ To whom correspondence should be addressed (email: emiliani@unipg.it ). 


\begin{abstract}
$\beta$-Hexosaminidase is a soluble glycohydrolase involved in glycoconjugate degradation into lysosomes, nevertheless its localization has also been described in cytosol and plasma membrane. Recently we demonstrated the presence of Hex associated to human fibroblast plasma membrane as mature form and functionally active towards GM2 ganglioside. In this study Hex was analysed in lysosomal membrane-enriched fraction, obtained by purification from highly purified human placenta lysosomes. Results demonstrate the presence of mature Hex associated to lysosomal membrane and displaying, as the plasma membrane (PM) associated form, an acidic optimum $\mathrm{pH}$. When subjected to carbonate extraction, the enzyme behave as a peripheral membrane protein, while Triton $\mathrm{X}-114$ phase separation confirmed its partial hydrophilic nature, characteristics that are in common with the PM-associated Hex. Moreover 2D electrophoresis indicated a slight difference in pl of $\beta$-subunits in the membrane and the soluble forms of the lysosomal Hex. These data reveal a new aspect of the Hex biology and suggest that a fully processed membrane-associated form of Hex is translocated from the lysosomal to the plasma membrane by an as yet unknown mechanism. We present a testable hypothesis that at the cell surface Hex changes the composition of glycoconjugates that are known to be involved in intercellular communication and signaling.
\end{abstract}

Key words: $\beta$-hexosaminidase, lysosomal membrane, membrane associated glycohydrolases.

Abbreviations used: CPK: creatine phosphokinase; GAPDH: glyceraldehyde 3phosphate dehydrogenase; $\beta$-Gluc: $\beta$-glucosidase; Hex: $\beta$-hexosaminidase; LAMP-2: lysosomal associated membrane protein 2; LM: lysosomal membrane; $\alpha$-Man: $\alpha$ -

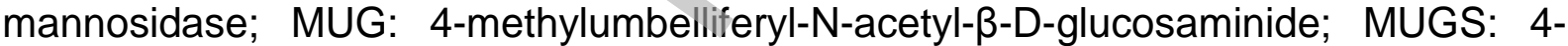
methylumbelliferyl-N-acetyl- $\beta$-D-glucosaminide-6-sulphate; $\mathrm{PL}$ : purified human placenta lysosomes; PM: plasma membrane.






\section{INTRODUCTION}

In the past glycohydrolases were believed to be mainly concentrated inside endosomal/lysosomal compartments where take part to the degradation of macromolecules into monomeric subunits [1,2]. Nevertheless, new studies show the presence of glycohydrolases at the plasma membrane (PM) and point to their potential role in modifying glycosphingolipids during signaling and cellular communication [3,4]. For instance, evidence for PM sialidase Neu3 activity towards gangliosides exposed to the surface of adjacent cells has been recently demonstrated by co-culture experiments $[5,6]$. Moreover, the presence of the lysosomal sialidase Neu1 anchored to both lysosomal and plasma membranes has been established and an important immunoregulatory role for this enzyme has been suggested $[7,8]$. In particular the translocation of sialidase Neu1 from lysosomes to PM has been observed during T-cell activation, where its ability to desialylate GM3 is required for IL-4 production in activated T-cells [9-11].

$\beta$-Hexosaminidase (Hex, EC 3.2.1.52) is an acidic glycohydrolase that catalyses the cleavage of terminal $\beta-\mathrm{N}$-acetylglucosamine or $\beta-\mathrm{N}$-acetylgalactosamine from a broad range of glycoconjugated substrates into lysosomes $[12,13]$. However, the presence of Hex has also been described in cytosol [14] and associated to PM of different cell populations, such as ascidia and Drosophila melanogaster sperm [15-17], human erythrocytes [18], laeukaemic cells [19], lymphocytes and monocytes purified from peripheral blood of multiple sclerosis patients [20]. In normal human tissues there are two major Hex isoenzymes: the heterodimer Hex A $(\mathrm{pl}=4,8)$ and the homodimer Hex $\mathrm{B}(\mathrm{pl}=6,9)$ [21]. Minor forms of Hex, characterized by intermediate $\mathrm{pl}$, have also been described in both normal and pathological cells [22]. Hex isoenzymes originate from the association of two different subunits, $\alpha$ and $\beta$, which are encoded by two evolutionarily related genes mapped on chromosome 15 and 5 , respectively $[23,24]$. Subunit dimerisation occurs into the endoplasmic reticulum, where neo-synthesized precursors form of Hex $A(\alpha \beta)$.and Hex $B(\beta \beta)$ undergo to extensive post-translational modifications such as glycosylation and culminate in the final proteolytic processing into lysosomes. The pro- $\alpha$ subunit is cleaved into $\alpha_{m}$ and $\alpha_{p}$ polypeptides while the mature $\beta$-subunit is composed of three polypeptides, $\beta_{a}, \beta_{b}$ and $\beta_{p}[21,25]$.

In a recent study we demonstrated the existence of a mature form of Hex $A$ associated with the PM of human fibroblasts and proved its ability to hydrolyse the natural substrate GM2 [26]. This observation suggests that PM-associated Hex should have a lysosomal origin, in fact only into lysosomes this enzyme undergoes to the final maturative process [21]. It is evident that the presence of Hex, as that of other acidic (lysosomal origin) glycohydrolases open new perspectives on the role of these enzymes.

In this study we demonstrate an association of mature Hex with the lysosomal membrane (LM). To this end, highly purified lysosomes were further processed in order to remove the soluble content and to recover purified lysosomal membraneenriched fraction. Moreover the nature of the association of the Hex to lysosomal membrane was further elucidated. Our results show that a fraction of fully processed 
forms of Hex A and Hex B isoenzymes are non-covalently attached to the inner aspect of the lysosomal membrane. 


\section{EXPERIMENTAL}

\section{Materials}

4-Methylumbelliferyl- $\beta-N$-acetylglucosaminide-6-sulphate (MUGS) was from Toronto Research Chemicals Inc. 4-Methylumbelliferyl- $\beta-N$-acetylglucosaminide (MUG), 4methylumbelliferyl- $\alpha$-mannopyranoside, 4-methylumbelliferyl- $\beta$-glucoside, $\quad$ 4methylumbelliferone, Protease Inhibitor Cocktail for Mammalian Cell Extracts, the detergents Triton X-114, NP-40, ASB-14, monoclonal anti-rabbit IgG HRP conjugate, polyclonal goat anti-mouse IgG HRP conjugate and monoclonal anti-goat/sheep lgG HRP conjugate, were from Sigma-Aldrich Fine Chemicals Co. Monoclonal mouse anti-LAMP-2 was from Santa Cruz Biotechnology, Inc. Diethylaminoethyl cellulose (DEAE) was from Whatman Biochemicals, Maidstone, Kent, UK. ECL, IPG strips, ExcelGel 2-D Homogeneous 12.5, 2-D Clean-Up Kit, Carbamylate Calibration Kit for 2-D were from Amersham Bioscencies, Aylesbury, Buckinghamshire, UK. Trans-Blot Nitrocellulose Membrane, bovine serum albumin and Bio-Rad protein assay reagent were from Bio-Rad Laboratories, Segrate-Milano. Centricon YM-10 were from Amicon, Millipore. All other reagents were of analytical grade.

\section{Lysosomal membrane-enriched fraction preparation}

Purified human placenta lysosomes (PL), $2 \mathrm{ml}$, obtained from fresh human placenta by a Percoll gradient as described [27], were thawed and mixed with $40 \mu \mathrm{l}$ of protease inhibitor cocktail. The mixture was sonicated ( 3 times for $15 \mathrm{~s}$ each) and diluted up to $10 \mathrm{ml}$ with $10 \mathrm{mM}$ sodium phosphate buffer $(\mathrm{Na} / \mathrm{P}), \mathrm{pH}$ 6.0. This lysosomal homogenate was subjected to ultracentrifugation at $4^{\circ} \mathrm{C}$ for $2 \mathrm{~h}$ at 183000 $\boldsymbol{g}$ in a Beckman Optima Max MLS-50 rotor, and the supernatant (S1) and the pellet that contained the enriched lysosomal membranes $(\mathrm{P} 1)$ were separated. $\mathrm{P} 1$ was resuspended in $0.5 \mathrm{ml}$ of $10 \mathrm{mM} \mathrm{Na} / \mathrm{P} \mathrm{pH} 6.0$ in presence of protease inhibitors, sonicated as above and diluted up to $10 \mathrm{ml}$ with the same buffer. Subsequently it was centrifuged at $4{ }^{\circ} \mathrm{C}$ for $2 \mathrm{~h}$ at $129000 \mathrm{~g}$ using the same rotor as above. This yielded S2 supernatant and P2 pellet fractions. The latter was extracted once more and supernatant S3 and pellet P3 fractions were obtained.

\section{Determination of enzyme activity and protein concentration}

Total Hex and Hex A activity was measured using $3 \mathrm{mM} \mathrm{MUG}$ and $3 \mathrm{mM}$ MUGS, respectively, in $0.1 \mathrm{M}$ citric acid/0.2 $\mathrm{M}$ disodium phosphate buffer, $\mathrm{pH} 4.5$ [28].

Optimum $\mathrm{pH}$ of Hex in lysosomal membrane-enriched fraction and Hex isoenzymes, recovered after DEAE-chromatography, was determined using the substrate MUG in $0.1 \mathrm{M}$ citric acid/0.2 M disodium phosphate buffers at different $\mathrm{pH}$ values ranging from $\mathrm{pH} 3.5$ to 7.5 .

Thermal stability of Hex isoenzymes, recovered after DEAE-chromatography, was determined by incubating samples at $52^{\circ} \mathrm{C}$ for $1 \mathrm{~h}$. Samples were cooled on ice for 1 $h$ and then assayed for Hex activity by using the MUG substrate. 
The activities of acid $\alpha$-mannosidase ( $\alpha$-Man, EC 3.2.1.24) and $\beta$-glucosidase ( $\beta$ Gluc, EC 3.2.1.45) were determined using $3 \mathrm{mM}$ solutions of corresponding 4methylumbelliferyl-glycoside substrates as previously described [29,30].

Fluorescence of the liberated 4-methylumbelliferone was measured using a Perkin Elmer LS B50 fluorimeter (excitation, $360 \mathrm{~nm}$; emission, $446 \mathrm{~nm}$ ). One enzymatic unit $(U)$ is the amount of enzyme that hydrolyses $1 \mu$ mole of substrate/min at $37^{\circ} \mathrm{C}$.

Protein concentration was determined by the method of Bradford [31] using bovine serum albumin as standard.

Specific activity was expressed as $\mathrm{mU} / \mathrm{mg}$ of protein.

\section{DEAE-chromatography}

Soluble lysosomal content S1 and lysosomal membrane-enriched fraction P3 were resuspended with $0.1 \%(\mathrm{v} / \mathrm{v}) \mathrm{NP}-40$ in $10 \mathrm{mM} \mathrm{Na} / \mathrm{P} \mathrm{pH} \mathrm{6.0,} \mathrm{sonicated} \mathrm{and} \mathrm{centrifuged}$ at $14000 \boldsymbol{g}$ for $15 \mathrm{~min}$. The recovered supernatants were analyzed by ion-exchange chromatography on DE-52 DEAE-cellulose as previously described [28]. Briefly, a 1 $\mathrm{ml}$ column was equilibrated with $10 \mathrm{mM} \mathrm{Na} / \mathrm{P}$ buffer, $\mathrm{pH} \mathrm{6.0}$; protein retained by the column was eluted using a linear $0.0-0.5 \mathrm{M}$ gradient of $\mathrm{NaCl}$ in $50 \mathrm{ml}$ of the above buffer. Finally, the proteins were eluted with $1.0 \mathrm{M} \mathrm{NaCl}$ in the same buffer. The flow rate was $1 \mathrm{ml} / \mathrm{min}$. Fractions $(1 \mathrm{ml}$ each) were collected and assayed for the Hex activity with the MUG and MUGS substrates.

\section{SDS-PAGE and Western blotting analysis}

$\mathrm{PL}$ and fractions resulting from lysosomal membrane enrichment procedure (P1 and S1, P2 and S2, P3 and S3) were subjected to 12\% SDS-PAGE under reducing conditions according to Laemmli [32]. Proteins were transferred to nitrocellulose, and the $\alpha$ and $\beta$ peptides of Hex detected using respectively an antiserum specific for $\alpha$ subunit, raised to a mixture of synthetic peptides belonging to the sequence of mature human enzyme, and a goat anti- $\beta$-subunit raised to Hex B purified from human placenta [25]. The filter was also developed with a monoclonal antibody raised to LAMP-2. Blots were analyzed by ECL detection system and densitometric analysis performed using the ImageMaster2D software.

\section{Bioinformatics analysis}

Analysis of amino acid sequences of Hex $\alpha$-subunit (primary accession number $\underline{P 06865}$ ) and $\beta$-subunit (primary accession number P07686 ) was performed using free internet software. Prediction of transmembrane domains was performed using TMpred-Prediction of Transmembrane Regions and Orientation software (http://www.ch.embnet.org/software/TMPRED_form.html). Prediction of glycosylphosphatidylinositol (GPI)-anchor motifs was performed using big-PI Predictor GPI Modification Site Prediction software (http://mendel.imp.ac.at/gpi/gpi_server.html). For the prediction of fatty acyl- or prenyl-anchor motifs the following software were using: Myristoylator predicts $\mathrm{N}$ ùterminal myristoylation of proteins by neural networks 
(http://www.expasy.ch/tools/myristoylator/PrePS), and PrePS Prenylation Prediction Suite (http://mendel.imp.ac.at/sat/PrePS/index.html).

\section{$\mathrm{NaCl}$ and carbonate extractions}

Lysosomal membrane-enriched fraction $\mathrm{P} 3$ was resuspended in $0.1 \mathrm{M} \mathrm{Na}_{2} \mathrm{CO}_{3} \mathrm{pH}$ 11.5 [33] or in $10 \mathrm{mM} \mathrm{Na} / \mathrm{P}$ containing $1 \mathrm{M} \mathrm{NaCl} \mathrm{pH} \mathrm{6.0.} \mathrm{As} \mathrm{control,} \mathrm{fraction} \mathrm{P3} \mathrm{was}$ resuspended in $10 \mathrm{mM} \mathrm{Na} / \mathrm{P} \mathrm{pH}$ 6.0. After $30 \mathrm{~min}$ incubation on ice, samples were ultracentrifuge at $4{ }^{\circ} \mathrm{C}$ for $2 \mathrm{~h}$ at $129000 \mathrm{~g}$. Both supernatant and pellet were adjusted to the same final volume and analyzed by immunoblotting.

\section{Triton X-114 phase separation}

Triton X-114 phase separation was performed as described by Bordier [34]. Briefly, fraction $\mathrm{P} 3$ was resuspended in $0.2 \mathrm{ml}$ of $10 \mathrm{mM}$ Tris- $\mathrm{HCl} \mathrm{pH} 7.4$ containing $150 \mathrm{mM}$ $\mathrm{NaCl}$ and $0.6 \%(\mathrm{v} / \mathrm{v})$ of the detergent Triton $\mathrm{X}-114$ and incubated at $0{ }^{\circ} \mathrm{C}$ for $1 \mathrm{~h}$. Detergent-treated sample was then layered onto $6 \%(\mathrm{w} / \mathrm{v})$ sucrose cushion $(0.3 \mathrm{ml})$, incubated at $30{ }^{\circ} \mathrm{C}$ for $3 \mathrm{~min}$ and finally centrifuge d at $300 \mathrm{~g}$ for $3 \mathrm{~min}$. After centrifugation, the upper aqueous phase was recovered, re-extracted with $0.5 \%(\mathrm{v} / \mathrm{v})$ Triton X-114 and subjected to a second separation through the same sucrose cushion. The detergent and aqueous phases were adjusted to the same final volume and analyzed by immunoblotting.

\section{2-D Electrophoresis and Western blotting analysis of lysosomal membrane associated Hex}

Soluble lysosomal content S1 and lysosomal membrane-enriched fraction P3 were resuspended in $40 \mathrm{mM}$ Tris base, containing $2 \%(\mathrm{w} / \mathrm{v})$ SDS and $60 \mathrm{mM}$ DTT. Samples were heated at $95^{\circ} \mathrm{C}$ for $5 \mathrm{~min}$ and insoluble debris were removed by centrifugation. 2-D Clean-Up Kit was used for preparing concentrated protein samples, that were then resuspended in rehydration solution $(7 \mathrm{M}$ urea, $2 \mathrm{M}$ thiourea, $2 \%(\mathrm{w} / \mathrm{v})$ ASB-14, 0.5\% (v/v) IPG-buffer $\mathrm{pH} 3-10,40 \mathrm{mM}$ DTT) with the addition of carbamylated protein standards for 2-DE. Precast linear IPG-strips $11 \mathrm{~cm}, \mathrm{pH} 3-10$ were swollen for $14 \mathrm{~h} 30 \mathrm{~V}$ at $20^{\circ} \mathrm{C}$. Isoelectric fo cusing was conducted at $20^{\circ} \mathrm{C}$, with a current limit of $50 \mu \mathrm{A} / \mathrm{IPG}$-strip in a IPGphor IEF System from Amersham, according to the following steps: $1 \mathrm{~h} 200 \mathrm{~V}, 1 \mathrm{~h} 500 \mathrm{~V}, 1 \mathrm{~h} 1000 \mathrm{~V}, 0.5 \mathrm{~h} 4000 \mathrm{~V}$ (gradient), $6 \mathrm{~h} 4000 \mathrm{~V}$. After IEF the IPG-strips were transferred to equilibration buffer (6 M urea, 30\% (v/v) glycerol, 2\% (w/v) SDS, $50 \mathrm{mM}$ Tris- $\mathrm{HCl} \mathrm{pH} 8.8$ ) in presence of $1 \%(\mathrm{w} / \mathrm{v})$ DTT for $15 \mathrm{~min}$, then incubated in equilibration buffer with $4 \%(\mathrm{w} / \mathrm{v})$ iodoacetamide for further $15 \mathrm{~min}$. The second dimension was performed on ExcelGel 2-D Homogeneous 12.5 (Amersham Bioscience). The resolved proteins were transferred on nitrocellulose membrane using Multiphor II NovaBlot Unit (Amersham Bioscience). After blotting proteins were visualised by Ponceau red staining. The filter was then incubated with an anti-serum raised to Hex B [25] and developed by ECL. 


\section{RESULTS}

\section{Hex activity and isoenzymes in lysosomal membrane-enriched fractions}

Fractions enriched in lysosomal membranes were obtained from PL through three successive steps of sonication and centrifugation as described in the experimental section. For each of the three steps of the experimental procedure we recovered a pellet further enriched in lysosomal membrane (P1, P2, P3) and supernatant containing the soluble lysosomal content (S1, S2, S3). All P and S fractions were assayed for the Hex activity using two substrates, MUG and MUGS, the former being hydrolysed by both $\alpha$ - and $\beta$-subunits and is the latter specifically by the $\alpha$-subunit. We also assayed the activity of another soluble lysosomal glycohydrolase, $\alpha$-Man [29], and of the lysosomal membrane marker $\beta$-Gluc, [28,30]. All fractions displayed Hex activity toward both MUG and MUGS subtrates, with an acidic optimum pH 4.5. Results reported in Figure 1 show that the increasing purification level of lysosomal membrane achieved by three steps of sonication and ultracentrifugation give rise to a gradual increase of the specific activity of $\beta$-Gluc. On the contrary, the specific activity of $\alpha$-Man decreased progressively. In P3 it was only barely detectable. The specific activity of Hex, assayed toward the MUG substrate, engaged a peculiar behaviour: we observed a decrease from PL to P2 that can be attributed, as for $\alpha$-Man, to the removal of soluble Hex, and then, in P3 fraction we detected a reproducible enrichment of total Hex specific activity with respect to P2. A further step of sonication and ultracentrifugation of P3 fraction did not increase the specific activity of Hex (data not shown). A similar trend was detected also when Hex activity was assayed with the MUGS substrate, but the increase in specific activity in P3 fraction with respect to P2 was less pronounced than for MUG activity (Figure 1). The Hex isoenzyme pattern in lysosomal membrane preparation P3 and in soluble lysosomal content (S1) was investigated by DEAE-cellulose chromatography. The subunit composition in peaks of activity that were eluted from the column was calculated from the relative rates of hydrolysis of the MUG and MUGS substrates. With both fractions similar elution profiles were obtained. Hex $B$ ( $\beta \beta$ dimer, as demonstrated by its inability to hydrolyse MUGS substrate) was not retained by the column and Hex $A, \alpha \beta$ dimer, was eluted with a maximum activity at approximately $0.12 \mathrm{mM} \mathrm{NaCl}$. Nevertheless, the elution profiles disclosed different proportions of Hex B and Hex A between membrane associated and soluble form (Table 1). The same amounts of Hex activity (detected using MUG substrate) were loaded on the columns and the loss of the activity was attributed to an inactivation of $\alpha$-subunit during the purification procedure. To better characterize the Hex isoenzymes we determined the $\mathrm{pH}$ optimum and thermal stability of Hex B and Hex A eluted by ion-exchange chromatography of S1 and P3 fractions. Concerning the thermal stability and, thus, the relative isoenzyme contents, there were no differences between the soluble and the membrane-associated Hex forms (Table 1).

\section{SDS-PAGE and Western blotting analysis of Hex in lysosomal membrane- enriched fractions}

The pellets containing the enriched lysosomal membranes (P1, P2 and P3) and the supernatants containing the lysosomal matrix proteins (S1, S2 and S3) were 
analysed by Western blotting and immunodetection of Hex using a specific antiserum raised to placental Hex $B$ and able to detect specifically the $\beta$-subunit (Figure 2, panel A). A constant amount of protein was loaded in each well. As shown in the left hand column in this Figure, in PL, P1, P2, P3 and S1 fractions, different amounts of mature Hex $\beta$-subunit as indicated by a single band of approx. $28 \mathrm{kDa}[21,25]$ were detected. Densitometric analysis (shown in the right hand column in the same panel) indicated a trend in Hex $\beta$-subunit polypeptide abundance in the above fractions that was observed for the specific activity, with the MUG substrate. A strong enrichment was observed in fraction P3. Similar results were obtained when Hex $\alpha$-subunit was immunodetected (Figure 2, panel B): mature $\alpha$-subunit $(54 \mathrm{kDa})$ was found in all samples except for S3. The clear enrichment of this subunit in P3 as compared to P2 highlighted the presence of both mature Hex $\alpha$ - and $\beta$-subunits in the membraneassociated enzyme and suggested that the low enrichment of MUGS activity in P3 as compared to P2 may have been caused by an inactivation of Hex A during the fractionation. In order to verify the effectiveness of our lysosomal membrane enrichment procedure we also monitored LAMP-2, a typical lysosomal integral membrane protein [35] using the specific antibody (Figure 2, panel C). The results highlighted a gradual increase in the intensity of the LAMP-2 band up to 24-fold in P3 as compared to PL. In a separate experiment we repeated the sonication and ultracentrifugation steps for the fourth time but this did not produce any further enrichment of LAMP-2 in the final pellet (data not shown).

\section{Peripheral membrane protein extraction and Triton X-114 phase separation}

In order to understand the nature of the anchoring of the predominantly soluble matrix enzyme to the lysosomal membrane, we first analysed the amino-acid sequence of Hex subunits. Bioinformatic analysis (see materials and methods) of the Hex $\alpha$ - and $\beta$-subunit amino acid sequences did not reveal the presence of any motif compatible with the addition of GPI, fatty acyl or prenyl lipid bilayer anchors. In fact, no consensus sequences for these post-translational modifications have been found. Instead TMpred-Prediction of Transmembrane Regions and Orientation software highlighted the presence of two putative membrane-spanning domains (Met ${ }^{13}-\mathrm{Thr}^{31}$ and Val ${ }^{436}-\mathrm{Gln}^{458}$ ) in the Hex $\beta$-subunit and one hydrophobic amino acid stretch $\left(\right.$ Leu $\left.^{6}-\operatorname{Trp}^{24}\right)$ in the Hex $\alpha$-subunit, but it has been demonstrated that the amino acid sequences between $\mathrm{Met}^{13}-\mathrm{Thr}^{31}$ and $\mathrm{Leu}^{6}-\mathrm{Trp}^{24}$ in $\alpha$ - and $\beta$-subunits, respectively, are removed in endoplasmic reticulum by signal peptidase during $\mathrm{N}$-terminal signal peptide cleavage [13]. Crystallographic analysis of the Hex B structure showed that the Val436-Gin458 stretch comprises amino acid residues involved in subunit dimerization, a crucial event in acquiring the enzymatic activity [13].

Based on these considerations we examined the possibility that Hex may be associated with the lipid bilayer as a peripheral membrane protein. Using the procedure of Fujiki [33], aliquots of the lysosomal membrane-enriched fraction P3

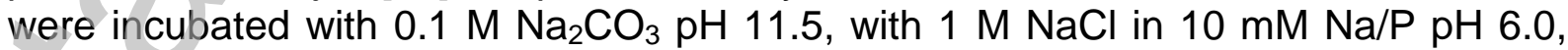
and with $10 \mathrm{mM} \mathrm{Na} / \mathrm{P} \mathrm{pH} \mathrm{6.0,} \mathrm{for} 30 \mathrm{~min}$. After the incubation, the mixtures were subjected to ultracentrifugation and the supernatant $(S)$ and pellet $(P)$ fractions obtained were analyzed by immunoblotting. Hex $\alpha$ - and $\beta$-subunits and LAMP-2 polypeptides were as before. The results (Figure 3 ) demonstrated an almost 
complete solubilisation of both $\mathrm{Hex} \alpha$ - and $\beta$-subunits in the presence of sodium carbonate. Both $\alpha$ - and $\beta$-subunit bands appeared in the S fraction whereas LAMP-2 was completely recovered in the insoluble $P$ fraction. In contrast, the treatments of the P3 fraction with the buffered $1 \mathrm{M} \mathrm{NaCl}$ and the buffer alone caused no appreciable solubilisation of the $\operatorname{Hex} \alpha$ - and $\beta$-subunits or of LAMP-2.

To obtain more information about the nature of the interaction between Hex enzyme and lipid bilayer we also performed Triton X-114 extraction of P3 fraction followed by aqueous/detergent phase separation. The detergent (Det) and aqueous (Aq) phases obtained after centrifugation were analyzed by immunoblotting. As shown in Figure 4, Hex $\alpha$ - and $\beta$-subunits partitioned in the aqueous phase, whereas LAMP-2 was present exclusively in the detergent phase as expected.

\section{Comparative analysis of soluble and membrane-associated Hex by 2-D electrophoresis}

To investigate possible differences between soluble and membrane-associated Hex, we performed 2-D electrophoresis and Western blotting analysis of both S1 and P3 fractions. Creatine phosphokinase (CPK) and glyceraldehyde 3-phosphate dehydrogenase (GAPDH) carbamylated standards provided a series of spots across a pl range of 4.9-7.1 and 4.7-8.3 respectively, which allowed the identification of $\mathrm{pl}$ of the protein by ImageMaster2D analysis. Spots identified on the blot by the specific antibody raised to Hex $B$, are pointed out in Figure 5. The results obtained after Western blotting analysis of the lysosomal matrix protein (Figure 5A) demonstrated the presence of two spots of same apparent molecular weight with pls of 6.00 and 6.66, corresponding to the mature $\operatorname{Hex} \beta_{\mathrm{a}}$ and $\beta_{\mathrm{b}}$-subunits, respectively [21].

These polypeptides were generated by the final proteolytic processing of Hex $B$ precursor that takes place in lysosomes [36]. The 2-D pattern of P3 (Fig. 5B) showed two spots of slightly different molecular weight and characterized by pls of 5.80 and 6.63. Analogous experiments performed using specific antibody raised to Hex A did not reveal any differences between soluble and membrane associated Hex $\alpha$-subunit (data not shown). 


\section{DISCUSSION}

Glycosphingolipids are ubiquitous membrane components of the eukaryotic cells that are abundant in the plasma membrane where they function as modulators of signal transduction regulating the proliferation, survival, and differentiation of the cells [37]. These lipids play key role as signaling molecules in both physiological and pathological processes regulating cell-to-cell and/or cell-environment interactions [3, 38]. Several recent studies revealed the presence of glycohydrolases not only in lysosomes but also at cell surface $[5,18,39,40]$. They stress the potential role of a remodelling of glycosphingolipids during cellular processes [6,7]. In a recent study we demonstrated that a mature form of hexosaminidase (Hex A isoenzyme) is associated to the human fibroblast PM and is catalytically active toward its natural substrate GM2 [26].

Here we demonstrate that lysosomal membranes that were purified from human placenta lysosomes [27] by repeated cycles of sonication and sedimentation in the ultracentrifuge also contain mature Hex isoenzymes in non covalently attached forms. It is conceivable that the procedure used here for the purification of the lysosomal membrane may result in a contamination of the final preparation with lipofuscin-like lysosomal inclusions which tend to sediment with the membranes. However, Hex enzymes are not present in the lipofuscin-like lysosomal inclusion body [41], therefore this kind of contamination is rather unlikely.

We assayed Hex activity with MUG and MUGS substrates and examined the presence of the two polypeptides, $\alpha$ and $\beta$, that constitute the Hex isoenzymes using specific antibodies in all fractions obtained during the purification. The results revealed that in the first two steps a major portion of Hex behaved as a soluble lysosomal enzyme similar to $\alpha$-Man, which was used as control. In the third step Hex, unlike $\alpha$-Man, behaved as a lysosomal membrane-associated protein and displayed an enrichment comparable to that of. $\beta$-Gluc. The latter is known to bind to the lysosomal integral membrane protein LIMP-2 [42]. The conclusion is that a significant amount of Hex is associated with the lysosomal membrane. A further step of sonication and centrifugation was not useful to detach this fraction of the enzyme from the membrane since it resulted in a selective loss of the enzymatic activity of the $\alpha$-subunit. This was demonstrated by a rapid decrease in MUGS activity, but not in the amount of $\alpha$-polypeptide that was detected by Western blotting.

Lysosomal membrane-associated Hex activity displayed an acidic optimum $\mathrm{pH}$ and thermal stability, as the soluble counterparts. Western blotting analysis clearly demonstrated that both $\alpha$ - and $\beta$-subunits associated to lysosomal membrane fraction in fully processed forms. In an attempt to elucidate the isoenzyme composition of lysosomal membrane-associated Hex we run a DEAE cellulose chromatography of P3 fraction. The subunit composition of peaks eluted from the column was determined by assay of the eluates with MUG and MUGS substrates. This analysis clearly revealed the presence of both Hex $A$ and Hex $B$ isoenzymes, eluting at the same position as the soluble lysosomal counterpart. The relative amount of Hex $A$ and $B$ is different between the soluble and the lysosomal membrane-enriched fraction 
P3 being Hex $B$ the predominant form, but this last can be attributed to the instability of $\alpha$-subunit activity.

Bioinformatic analysis of the Hex $\alpha$ - and $\beta$-subunit amino acid sequences excluded the presence of sequence compatible with GPI-anchor protein, fatty acylated or prenylated proteins because no post-translational modification consensus sequences have been found. In order to verify if Hex behave as a peripheral membrane protein associated with the lipid bilayer by ionic and/or hydrogen interaction involving transmembrane proteins or phospholipids resident in LM, lysosomal membraneenriched fraction $\mathrm{P} 3$ was treated with $1 \mathrm{M} \mathrm{NaCl}$ or with sodium carbonate at the extreme $\mathrm{pH}$ value of 11.5 [33]. In the first condition Hex remained associated to LM as well as the lysosomal transmembrane protein LAMP-2, while the extreme $\mathrm{pH}$ conditions produced the complete solubilisation of both Hex subunits but not of the integral lysosomal membrane LAMP-2 (Figure 4). Triton X-114 phase separation of lysosomal membrane-enriched fraction P3 allowed the completed segregation of Hex $\alpha$ - and $\beta$-subunits in aqueous phase (Figure 5), thus demonstrating the hydrophilic nature of Hex subunits [34]. In contrast, as expected LAMP-2 protein partitioned completely into the detergent phase. All together these findings support the hypothesis that a portion of the lysosomal Hex behaves as a peripheral membraneassociated protein.

Comparative analysis by 2-D electrophoresis and Western blotting revealed that mature $\beta_{\mathrm{a}}$ and $\beta_{\mathrm{b}}$ polypeptides that were recovered in the lysosomal membraneassociated form displayed a slightly different apparent molecular weight and $\mathrm{pl}$ as compared to their soluble lysosomal counterparts (Figure 3B). In contrast, no differences were observed between the soluble and the membrane-associated forms of the $\alpha$-subunit (data not shown). We speculate that the observed differences between the apparent molecular weights and isoelectric points of the matrix and the membrane-associated forms of Hex $\beta$-polypeptides could be due to an as yet unknown post-translational modification. This may result in binding to a component of the membrane.

This study demonstrated the existence of membrane-associated forms of both Hex A and Hex $B$ isoenzymes in lysosomal membranes from human placenta. The lysosomal membrane-associated forms displayed the same catalytic properties as the soluble forms and also the enzyme that has been found at the plasma membrane in an earlier study [15]. Therefore, we consider the existence of two pools of mature Hex: a membrane-associated and a soluble. The membrane-associated Hex is present in both lysosomal and plasma membranes. It should be of interest to examine the pathway delivering the membrane-associated lysosomal Hex to the cell surface and the possible functions of the cell surface-associated enzyme in modulating the glycolipid pattern at the cell boundary.

\section{ACKNOWLEDGEMENTS}

Work supported by COFIN-PRIN 2004050497_002 and FIRB RBAUO1MSFR grants to C.E. 


\section{REFERENCES}

1 Gravel, R.A., Clarke, J.T.R., Kaback, M.M., Mahuran, D.J., Sandhoff, K., Suzuki, K. (1999) The Metabolic Basis of Inherited Disease (Scriver, C.R., Beaudet, A.L., Sly, W.S., Valle, D.L., Eds.), pp. 2839-2879, McGraw Hill, New York.

2 De Duve, C. (1983) Lysosomes revisited. Eur J Biochem. 137, 391-397.

3 Hakomori, S. (1996) Tumor malignancy defined by aberrant glycosylation and sphingo(glyco)lipid metabolism. Cancer Res. 56, 5309-5318.

4 Hakomori, S. (2003) Structure, organization, and function of glycosphingolipids in membrane. Curr Opin in Hematol. 10, 16-24.

5 Papini, N., Anastasia, L., Tringali, C., Croci, G., Bresciani, R., Yamaguchi, K., Miyagi, T., Preti, A., Prinetti, A., Prioni, S., Sonnino, S., Tettamanti, G., Venerando, B., and Monti, E. (2004) The plasma membrane-associated sialidase MmNEU3 modifies the ganglioside pattern of adjacent cells supporting its involvement in cell-to-cell interactions. J. Biol. Chem. 279, 16989-16995.

6 Valaperta, R., Chigorno, V., Basso, L., Prinetti, A., Bresciani, R., Preti, A., Miyagi, T., Sonnino, S. (2006) Plasma membrane production of ceramide from ganglioside GM3 in human fibroblasts. FASEB J. 20, 1227-1229.

7 Lukong, K.E., Seyrantepe, V., Landry, K., Trudel, S., Ahmad, A., Gahl, W.A., Lefrancois, S., Morales, C.R., Pshezhetsky, A.V. (2001) Intracellular distribution of lysosomal sialidase is controlled by the internalization signal in its cytoplasmic tail. J. Biol. Chem. 276, 46172-46181.

8 Wang, P., Zhang, J., Bian, H., Wu, P., Kuvelkar, R., Kung, T.T., Crawley, Y., Egan, R.W., Billah, M.M. (2004) Induction of lysosomal and plasma membrane-bound sialidases in human T-cells via T-cell receptor. Biochem. J. 380, 425-433.

9 Chen, X.P., Enioutina, E.Y., Daynes, R.A. (1997) The control of IL-4 gene expression in activated murine $T$ lymphocytes: a novel role for neu-1 sialidase, $\mathrm{J}$ Immunol. 158, 3070-3080.

10 Chen, X.P., Ding, X., Daynes, R.A. (2000) Ganglioside control over IL-4 priming and cytokine production in activated T cells. Cytokine 12, 972-985.

11 Liang, F., Seyrantepe, V., Landry, K., Ahmad, R., Ahmad, A., Stamatos, N.M., Pshezhetsky, A.V. (2006) Monocyte differentiation up-regulates the expression of the lysosomal sialidase, Neu1, and triggers its targeting to the plasma membrane via major histocompatibility complex class II-positive compartments. J Biol Chem. 287, 27526-27538.

12 Lemieux, M.J., Mark, B.L., Cherney, M.M., Withers, S.G., Mahuran, D.J., James, M.N. (2006) Crystallographic structure of human $\beta$-hexosaminidase A: interpretation of Tay-Sachs mutations and loss of GM2 ganglioside hydrolysis. J. Mol. Biol. 359, 913-929.

13 Mark, B.L., Mahuran, D.J., Cherney, M.M., Zhao, D., Knapp, S., James, M.N. (2003) Crystal structure of human $\beta$-hexosaminidase B: understanding the molecular basis of Sandhoff and Tay-sachs disease. J. Mol. Biol. 327, 10931109.

14 Gao, Y., Wells, L., Comer, F.I., Parker, G.J., Hart, G.W. (2001) Dynamic Oglycosylation of nuclear and cytosolic proteins: cloning and characterization of 
a neutral, cytosolic beta-N-acetylglucosaminidase from human brain. J. Biol. Chem. 276, 9838-9845.

15 Lambert, C.C. (1989) Ascidian eggs release glycosidase activity which aids in the block against polyspermy. Development 105, 415-420.

16 Pasini, M.E., Cattaneo, F., Pinto, M.R., De Santis, R., Perotti, M.E. (1999) Plasma membrane association and preliminary characterization of Drosophila sperm surface glycosidases. Mol. Repr. Devel. 52, 166-173.

17 Cattaneo, F., Ogiso, M., Hoshi, M., Perotti, M.E., Pasini, M.E. (2002) Purification and characterization of the plasma membrane glycosidases of Drosophila melanogaster spermatozoa. Insect Bioch. Mol. Biol. 32, 929-941.

18 Massaccesi, L., Lombardo, A., Venerando, B., Tettamanti, G., Goi, G. (2007) Isoenzyme pattern and partial characterization of hexosaminidases in the membrane and cytosol of human erythrocytes, Clin. Biochem. 40, 467-477.

19 Martino, S., Emiliani, C., Orlacchio, A., Hosseini, R., Stirling, J.L. (1995) $\beta-N-$ acetylhexosaminidase $A$ and $S$ have similar sub-cellular distributions in HL-60 cells. Biochem. Biophys. Acta 1243, 489-495.

20 Orlacchio, A., Martino, S., Sarchielli, P., Gallai, V., Emiliani, C. (1998) Beta-Nacetylhexosaminidase in peripheral blood lymphocytes and monocytes in the different forms and stages of multiple sclerosis. J. Neurochem. 71, 1168-1176.

21 Mahuran, D.J. (1999) Biochemical consequences of mutations causing the GM2 gangliosidoses, Biochem. Biophys. Acta. 1455, 105-138.

22 Mahuran, D.J. (1990) Characterization of human placental $\beta$-Hexosaminidase I. J. Biol. Chem. 265, 6794-6799.

23 Proia, RL., Soravia, E. (1987) Organization of the gene encoding the human beta-hexosaminidase alpha-chain. J. Biol. Chem. 262, 5677-5681.

24 Proia, RL. (1988) Gene encoding the human beta-hexosaminidase beta chain: extensive homology of intron placement in the alpha- and beta-chain genes. Proc. Natl. Acad. Sci. USA 85, 1883-1887.

25 Hasilik, A., Neufeld, E.F. (1980) Biosynthesis of lysosomal enzymes in fibroblasts. Synthesis as precursors of higher molecular weight. J. Biol. Chem. 255, 4937-4945.

26 Mencarelli, S., Cavalieri, C., Magini, A., Tancini, B., Basso, L., Lemansky, P., Hasilik, A., Li, Y.T., Chigorno, V., Orlacchio, A., Emiliani, C., Sonnino, S. (2005) Identification of plasma membrane associated $\beta$-Hexosaminidase $A$, active towards GM2 ganglioside, in human fibroblasts. FEBS Letters 579, 5501-5506.

27 Diettrich, O., Gallert, F., Hasilik, A. (1996) Purification of lysosomal membrane proteins from human placenta. Eur. J. Cell Biol. 69, 99-106.

28 Emiliani, C., Beccari, T., Tabilio, A., Orlacchio, A., Hosseini, R., Stirling, J.L. (1990) An enzyme with properties similar to those of beta Nacetylhexosaminidase $\mathrm{S}$ is expressed in the promyelocytic cell line HL-60. Biochem. J. 267, 111-117.

29 Emiliani, C., Martino, S., Stirling, J.L., Maras, B., Orlacchio, A. (1995) Partial sequence of the purified protein confirms the identity of cDNA coding for human $\beta$-mannosidase B. Biochem. J. 305, 363-366.

30 Leonova, T., Grabowsky, G.A. (2000) Fate and sorting of acid $\beta$-glucosidase in transgenic mammalian cells. Mol. Genet. Metabol. 70, 281-294. 
31 Bradford, M.M. (1976) A rapid and sensitive method for the quantitation of microgram quantities of protein utilizing the principle of protein-dye binding. Anal. Biochem. 72, 248-254.

32 Laemmli, U.K. (1970) Cleavage of structural protein during the assembly of the head of bacteriophage T4. Nature 227, 680-685.

33 Fujiki, Y., Hubbard, A.L., Fowler, S., Lazarow, P.B. (1982) Isolation of intracellular membranes by means of sodium carbonate treatment: application to endoplasmic reticulum. J. Cell Biol. 93, 97-102

34 Bordier, C. (1981) Phase separation of Integral Membrane Proteins in Triton X114 Solution. J. Biol. Chem. 256, 1604-1607.

35 Eskelinen, E.L., Tanaka, Y., Saftig, P. (2003) At the acicic edge: emerging function for lysosomal membrane proteins. Trends in Cell Biol. 13, 137-145.

36 Ahn, K., Yeyeodu, S., Collette, J., Madden, V., Arthur, J., Li, L., Erickson, A.H. (2002) An alternate targeting pathway for procathepsin $L$ in mouse fibroblasts. Traffic 3, 147-159.

37 Hakamori, S. (1990) Bifunctional role of glycosphingolipids. Modulators for transmembrane signaling and mediators for cellular interactions. J. Biol. Chem. 265, 18713-18716.

38 Hakamori, S. (2002) Glycosilation defining cancer malignancy: new wine in an old bottle. Proc. Natl. Acad. Sci. 99, 10231-10233.

39 Cordero, O.J., Merino, A., de la Cadena, M. P., Bugía, B., Nogueira, M., Viñuela, J.E., Martínez-Zorzano, V.S., de Carlos, A., Rodríguez-Berrocal, F.J. (2001) Cell surface human alpha-L-fucosidase. Eur. J. Biochem. 268, 33213331.

40 Goi, G., Bairati, C., Massaccesi, L., Lovagnini, A., Lombardo, A., Tettamanti, G. (2000) Membrane anchoring and surface distribution of glycohydrolases of human erythrocyte membranes. FEBS Lett. 473, 89-94.

41 Schröder, B., Elsässer, H-P., Schmidt, B., Hasilik, A. (2007) Characterisation of lipofuscin-like lysosomal inclusion bodies from human placenta. FEBS Lett. 581, $102-108$.

42 Reczek, D., Schwake, M., Schröder, J., Hughes, H., Blanz, J., Jin, X., Brondyk, W., Van Patten, S., Edmunds, T., Saftig, P. (2007) LIMP-2 is a receptor for lysosomal mannose-6-phosphate-independent targeting of betaglucocerebrosidase. Cell 131, 770-783. 
Table 1 Separation of A and B isoenzymes of Hex in soluble lysosomal content S1 and purified lysosomal membrane fraction P3 using DEAE-DE52 cellulose chromatography

\begin{tabular}{|c|c|c|c|c|c|c|c|}
\hline & \multicolumn{2}{|c|}{$\begin{array}{c}\text { \% of Hex activity } \\
\text { recovered from } \\
\text { DEAE }\end{array}$} & \multicolumn{2}{|c|}{$\mathrm{NaCl}(\mathrm{mM})^{\mathrm{b})}$} & $\underset{\text { optimum }^{\mathrm{c})}}{\mathrm{pH}}$ & \multicolumn{2}{|c|}{$\begin{array}{l}\text { Thermal } \\
\text { stability }\end{array}$} \\
\hline & S1 & P3 & S1 & P3 & S1 & S1 & P3 \\
\hline Hex B & $24 \pm 3$ & $49 \pm 4.5$ & - & - & 4.5 & $94 \pm 4$ & $90 \pm 4$ \\
\hline Hex A & $37 \pm 4$ & $14 \pm 2$ & 0.12 & 0.12 & & $39 \pm 5$ & $36 \pm 3$ \\
\hline
\end{tabular}

a) Values represent the \% of Hex activity towards MUG substrate recovered as Hex B and Hex A, with respect to the total MUG activity loaded. Same amounts of MUG activity was loaded on the column in each experiment.

b) Salt concentration required for Hex A elution within the gradient.

c) Optimum $\mathrm{pH}$ for Hex isoenzyme activity determined dissolving MUG substrate in buffers at different $\mathrm{pH}$ values ranging from $\mathrm{pH} 3.5$ to 7.5 .

d) Values represent the \% of residual MUG activity of Hex B and Hex A, after $1 \mathrm{~h}$ incubation at $52^{\circ} \mathrm{C}$, respected to non-heated contro ls.

The results represent the means of three independent experiments \pm S.D. 


\section{LEGEND TO THE FIGURES}

Figure 1 Specific activity of Iysosomal glycohydrolases during enrichment procedure

The histograms represent specific activities of total Hex, Hex A, $\alpha-$ Man and $\beta$-Gluc as detected in PL and in pellets P1, P2 and P3 that were obtained at three stages of the purification of lysosomal membranes from PL. The results represent means of three independent experiments \pm S.D.

Figure 2 Western blots and densitometric analysis of the fractions obtained from lysosomal membrane-enriched procedure

The same amounts of protein $(10 \mu \mathrm{g})$ of $\mathrm{PL}$ and of three stages of lysosomal membrane purification (pellets P1, P2 and P3) and constant aliquots (30 $\mu \mathrm{l})$ of supernatants S1, S2 and S3 from this purification were separated using SDS-PAGE. After blotting, polypeptides of Hex were detected with antisera against Hex $B(A)$, Hex a-subunit (B). For comparison, LAMP-2 was detected with the appropriate antibody (C). The detection was performed by ECL (the stripes on the left hand side) and densitometry using the ImageMaster2D software (the diagrams on the right hand side).

Figure 3 Extraction of Hex polypeptides from purified lysosomal membranes in the presence of $\mathrm{NaCl}$ and carbonate solutions

Aliquots of fraction P3 (10 $\mu \mathrm{g}$ protein) were incubated in the presence of $10 \mathrm{mM} \mathrm{Na} / \mathrm{P}$ $\mathrm{pH} 6.0$ (Control), $10 \mathrm{mM} \mathrm{Na} / \mathrm{P}, 1 \mathrm{M} \mathrm{NaCl} \mathrm{pH} 6.0(\mathrm{NaCl})$ or $0.1 \mathrm{M}$ sodium carbonate $\mathrm{pH} 11.5\left(\mathrm{Na}_{2} \mathrm{CO}_{3}\right)$ and separated into soluble (S) and membrane subfractions (P) using ultracentrifugation. Hex polypeptides were analysed in an untreated P3 aliquot $(\mathrm{T})$ and the subfractions using SDS-PAGE and Western blotting and anti-Hex $\mathrm{B}$, antiHex a-subunit antibodies. For comparison, LAMP-2 was detected with the appropriate antibody.

Figure 4 Partitioning of Hex isoenzymes and LAMP-2 using Triton X-114 phase separation

Fraction P3 (10 $\mu \mathrm{g}$ protein) were subjected to a Triton X-114 phase separation. After ultracentrifugation the aqueous (Aq) and detergent (Det) phases, and a non-treated aliquot of P3 (T) were analyzed by immunoblotting using anti-Hex B, anti-Hex $\alpha-$ subunit and anti-LAMP-2 antibodies.

Figure 5 Characterisation of Hex polypeptides in the soluble lysosomal content S1 and purified lysosomal membranes P3 using 2-D electrophoresis and Western blotting

Aliquots of $\mathrm{S} 1$ (A) and P3 fraction (B) containing the same amounts of Hex $(10 \mathrm{mU}$ as determined with the MUG substrate) were loaded on $11 \mathrm{~cm}$ IPG-strips pH 3-10 and separated by isoelectric focusing, and 12.5\% SDS-PAGE. After blotting, major $\beta-$ subunit polypeptides of Hex were detected using an anti-Hex $B$ antiserum as the primary antibody. The isoelectric points $(\mathrm{pl})$ of the detected spots were determined by a comparison with those of the CPK and GAPDH carbamylated standards. Image analysis was performed by using ImageMaster 2D. 
Figure 1

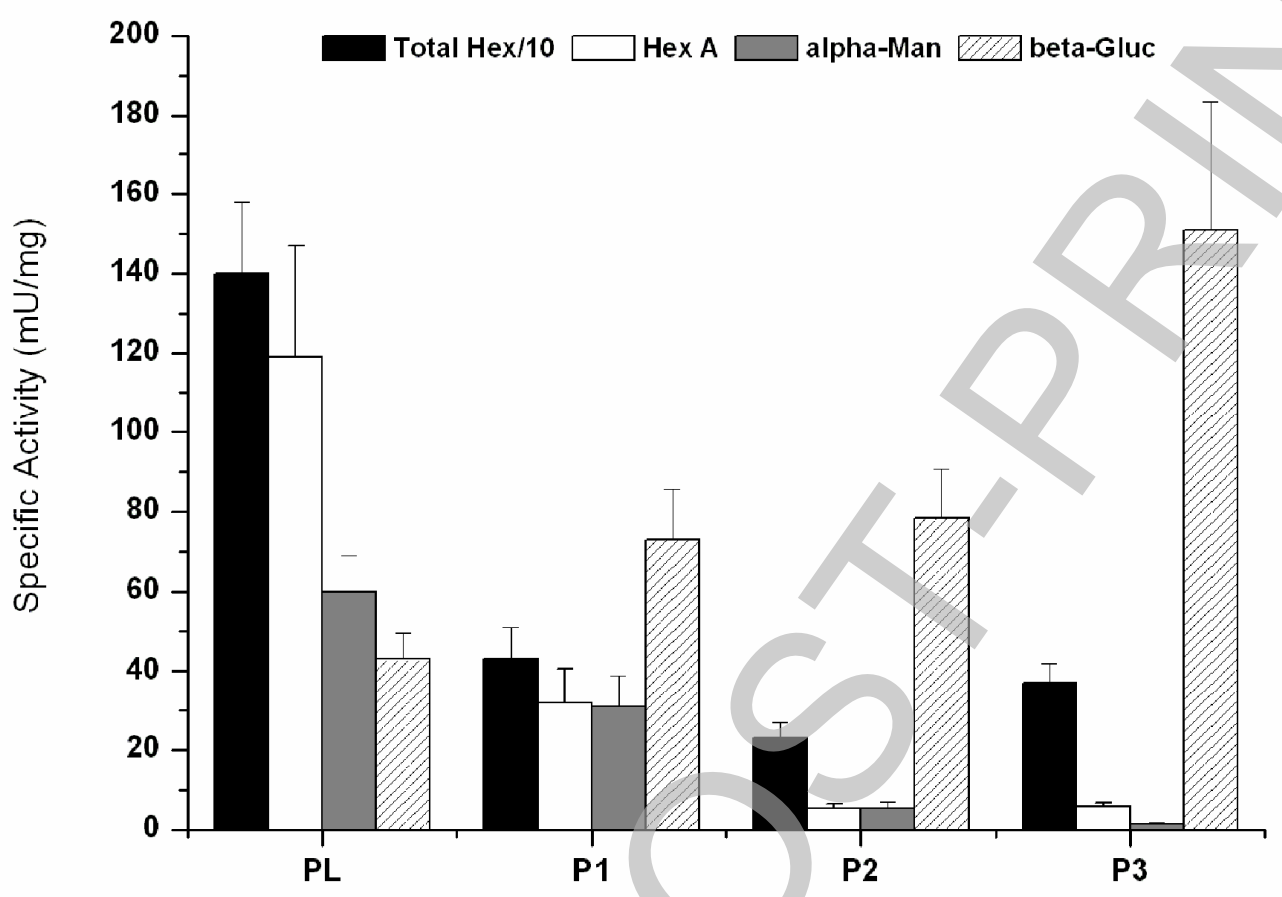




\section{Figure 2}

A

Fractions PL S1 P1 S2 P2 S3 P3

Hex $\beta$-subunit

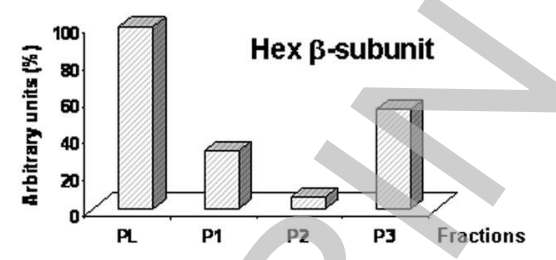

B
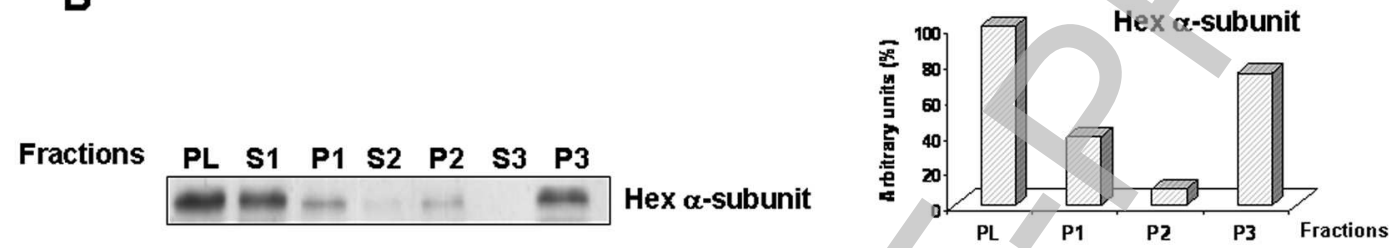

C

$\begin{array}{llllllll}\text { Fractions } & \text { PL } & \text { S1 } & \text { P1 } & \text { S2 } & \text { P2 } & \text { S3 } & \text { P3 }\end{array}$

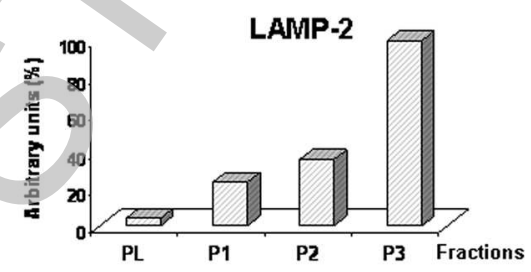

Licenced copy. Copying is not permitted, except with prior permission and as allowed by law.

' 2008 The Authors Journal compilation ' 2008 Biochemical Society 
Figure 3

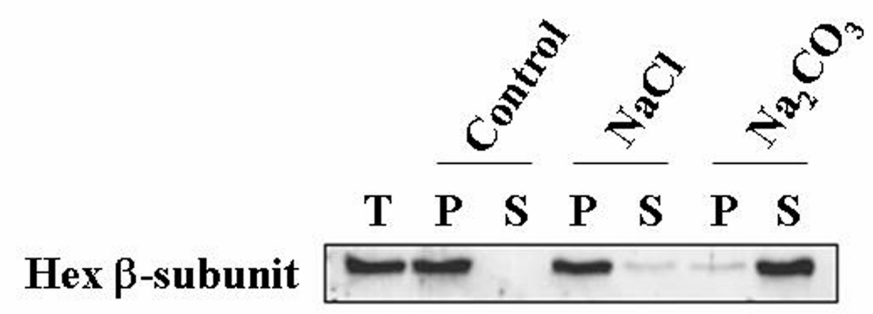

Hex $\alpha$-subunit $:-i=1-1$

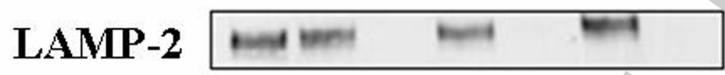


Figure 4
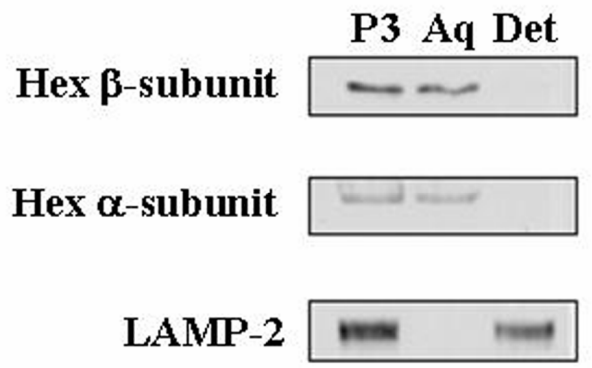
Figure 5

A

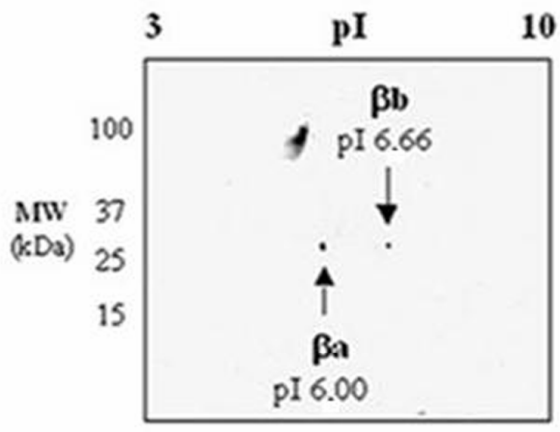

S1
B

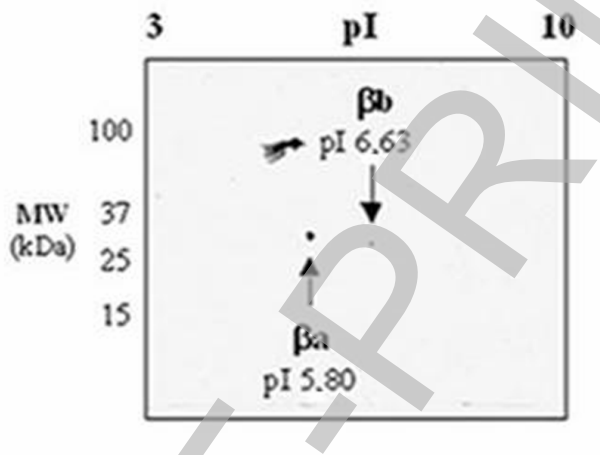

P3 